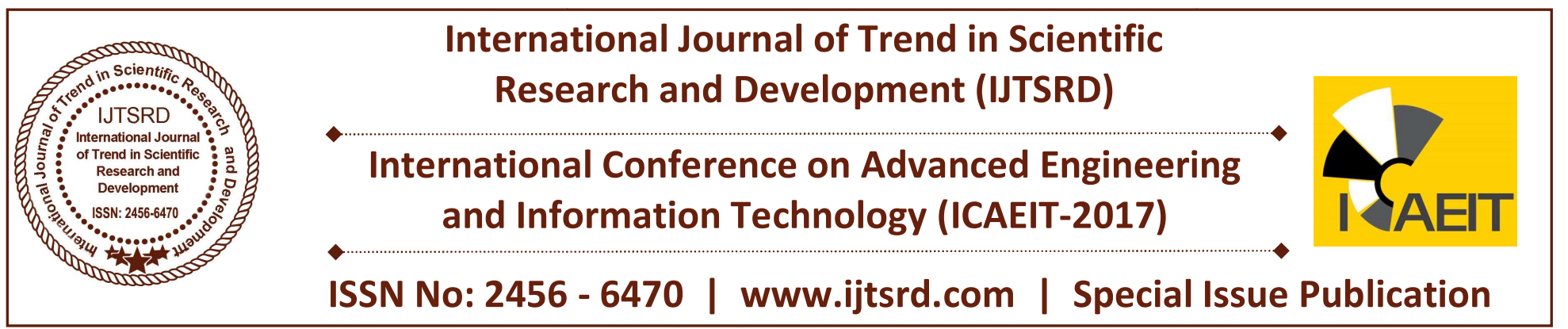

\title{
Green Sustainability Development for Industry Internet of Things in Railway Transportation Industry
}

\author{
Opeyemi Olajide Adebiyi ${ }^{1}$, Mia Torres-Dela Cruz ${ }^{2}$ \\ ${ }^{1}$ Universiti Teknologi Malaysia, Melaka, Malaysi \\ ${ }^{2}$ Faculty of Engineering and Technology, Linton University College, Malaysia
}

\begin{abstract}
Since the railway industry has become the primary consideration for technology upgrade, there is also the issue of the technology being green and sustainable. There is no global sustainability policies when the railway industry's technology is being upgraded. There is a need for a strategy to ensure that the upgrade, especially with IIoT, is implemented.
\end{abstract}

The research aims to analyse the current situation of green sustainability in business technologies; to develop sustainability policies appropriate to business processes where emerging technologies are applied or implemented in the future; and to create a strategic plan for green and sustainable development of emerging business technologies. The study is limited to green sustainability development of IIoT that is being used in the railroad transportation industry of Malaysia, its MRT, LRT and monorail. A proposed strategic plan will be developed to ensure a green and sustainable development for the Malaysian Railway Industry.

The paper will be an in depth study of the Malaysian railway industry in conjunction with the application of IIoT and sustainable development is to be done.

Keywords: Green, sustainability development, IIoT, railway industry, emerging technologies

\section{Introduction}

Green and sustainability policy development has become an ethical motivation as well as a strategic motivation for business establishments. Corporate social responsibility dictates that business organizations should do innovations but keeping green sustainability in mind. Railway transportation industry has an important role in the progress of a nation. This, too, like other industries, are improving in terms of technological updates. The problem today, however, is that emerging technologies in the railway industry do not have secure global sustainability policies. It is a must to apply new technologies to railway industry to improve mobility in this globalized and changing world [1]. One such technology applied to the railway industry is industrial internet of things (IIoT). This new technology when applied to the railway industry will improve operational efficiency, passenger experience and return on investment of operators.

Undeniably, there is new generation of eco-friendly train stations are laying down solid tracks for a sustainable future [2]. Strategies need to be developed so that there is an assurance that this technology is going to create a smart railway and a green and sustainable transportation industry. Another factor also considered is climate change, which brings climate-related disasters which has a high impact on business, such as higher raw material and energy costs, new environmental policies, and a growing number of customers who are taking into account organisation's environmental record, bringing business risks and demand for innovation in industries and requires new business strategies to reduce greenhouse gases to compete successfully in a carbonconstrained world. These strategies have to be harnessed to get incremental or transformational change and the appropriate strategy towards green 
sustainability with the use of IIoT in the railway transportation industry.

Since the British colonial era, there have been rail lines in West Malaysia, the West Coast Line runs from the Thai border to Singapore along the west coast of Peninsular Malaysia. The East Coast Line runs between Gemas south of KL to Kota Bharu on the north-east coast. It hauled freight, mostly bulk commodities such as cement and sugar, and some passengers with antiquated diesel electric engines.

Today, the modern rail transport of Malaysia is composed of three main systems, heavy rail (KTM Komuter), light rapid transit (LRT), and monorail, and an additional airport rail link. The biggest change has been the development of an additional system of an electric light rail system, and the expansion of the monorail system, based in Kuala Lumpur. It is still expected that the commuter rail system will continuously modernize and expand. It is also expected that because of this modernization, the passenger share will continue to increase [3].

The objectives of the research are to: analyse the current situation of green sustainability in business technologies; develop sustainability policies appropriate to business processes where emerging technologies are applied or implemented in the future; create a strategic plan for green and sustainable development of emerging business technologies.

The paper is concerned with green sustainability development of industrial internet of things (IIoT) that is being used in the railroad transportation industry of Malaysia. The study will focus on the Malaysian Railways which includes three passenger rail transportations, namely, MRT, LRT and monorail. A strategic plan will be developed to ensure a green and sustainable development for the Malaysian Railway Industry.

\section{IIoT in the Railway Industry}

The railway transportation industry has a very crucial role in Malaysia's mobility and economy. Because of this, it is a priority area for technology upgrade. This is why new technologies such as the industrial internet of things (IIoT) has been considered and applied to the railway industry. Techtarget.com has defined the Industrial Internet of Things (IIoT) as the use of Internet of Things (IoT) technologies in manufacturing.
Another name is Industrial Internet, (IIoT), is a combination of machine learning and big data technology, harnessing the sensor data, machine-tomachine (M2M) communication and automation technologies that were already used in industry settings for many years. The basis for IIoT is the premise that smart machines are much better than people in data communications and capturing data accurately and consistently. This data can enable companies to pick up on inefficiencies and problems sooner, saving time and money and supporting business intelligence efforts. IIoT has high potential for quality control, sustainable and green practices, supply chain traceability and overall supply chain efficiency [4].

Recent technological advances in networking have made smart trains a possibility, and it provides significant benefits when transporting goods, providing comfort and safety for passengers, and increasing the operator's return on investments (ROI). Successful implementation of IIoT can result in improved operational efficiency, enhanced automation, adaptability and safety, and better passenger experiences [5]. The emergence of the industrial internet of things (IIoT) in last few years has set the stage for a digital disruption of railways. The railway industry has already seen a major impact but one region that has seen less attention is the linked railway.

Pranav Misal [5] has identified some IIoT technologies that would help the railway industry. Some of them are: IIoT technologies will appear in real-time machine-to- machine (M2M) communication, signalling, train radios, line side communication, level-crossings, station information and security at the end points; IIoT will provide real time monitoring, analysis, control and maintenance; Trains will be interconnected through communication hubs, and data and instructions will flow among trains and the network control rooms to enable operators to utilize equipment, tracks and stations more efficiently; IIoT will reduce safety risks and operational expenses.

Kulkarni [6] stated that IIoT is a good technology for sustainability development because it is used in remote monitoring which will result in faster troubleshooting and issues identification. IIoT systems in railroad industry will exploit the lifespan of building systems - by leveraging data analytics capabilities to carry out predictive maintenance. It 
will enable Machine to Machine (M2M) communication, seamless connectivity and control by connecting hardware and software through the internet to provide more control on systems. Certainly there will be real time auto control to maintain highest possible energy efficiency and performance efficiency and optimum running of the machines, utilities, and different businesses. Business processes such as supply chain management (SCM), logistics, customer complaint management, production, traffic control, waste management, disaster management, pollution measurement from the supplier to the plant, on to the distributor, and to the manufactured product. Everything in and around the manufacturing operation will be connected enabling a true integration of business processes and technology.

\section{Green Sustainability for the Railway Industry}

Green sustainability is being green and sustainable at the same time. This is when products and services are maintained as green and at the same time being sustained or maintained for a long period of time or even indefinitely.

The words sustainable and green are often used interchangeably. But being "green" and being "sustainable" is not the same thing. Green is defined as "products and services that reduce health and environmental impacts compared to similar products and services used for the same purpose," says Steve Ashkin [7], president of The Ashkin Group and chairman of the Sustainability Dashboard.

While, sustainability can be represented with the triple- legged foundation representing environmental, social and financial responsibility, according to Jim Newman [8], owner of Newman Consulting Group.

"With green, our consideration about people and staff is limited to direct exposures from products or services," states Ashkin [7]. "Sustainability is a much broader term that talks about the implications of those products and services used over a much longer period of time, and considers social and financial impacts as well."

For any organization, this means green/sustainability goals must be defined, changes should be implemented and at the end, evaluate and measure their achievement. There is no right way to go green and move toward sustainability either, adds Ashkin
[7]. Start slowly and build from there. "Sustainability is a journey, not a destination," he says.

"When you're green, you don't dig in as deeply," Ashkin explains. "But if you're sustainable and you're buying a paper product, you're also asking: Where did this paper come from? What is it made of? Is it made out of illegally harvested wood? What forestry practices were employed?" A company that plants a new tree for everyone it cuts down is using sustainable forestry practices, for instance. As companies move down the sustainable path, documenting their results becomes very essential.

Fighting climate change means there has to be strategic objectives which includes the enhancement of energy efficiency, increase the use of renewable sources at the same time making sure that the reliability of energy supplies, securing the establishment of reliable energy

products and services and promoting green products and sustainable production. Today, the energy market is undergoing deep reforms while new advanced energy technologies and continuous environmental issues appear and requirements arising from European and international cooperation as well as various intergovernmental agreements are factors shaping and harmonizing the institutional and legislative framework of the energy markets (YPEKA, 2012)[8].

Indeed, sustainability has become a strategic imperative for companies in all industries if they are to continue to prosper and maintain a competitive edge. All companies need to develop a comprehensive understanding of sustainability and systematically work to incorporate that understanding into their ongoing operations and strategies, with the goal of realizing economic, environmental, and social equity benefits.

A thorough discussion on this challenge has been going on since the publication in 1987 of the Brundtland Report (Our Common Future)[9], where an adequate balance between economic growth and environmental protection was prescribed for reaching Sustainable Development-_ensure that humanity meets the needs of the present without compromising the ability of future generations to meet their own needs" [9]. The report stressed also the importance of "producing more with less"' (idem, p. 206), which is the base of the concept of "eco- efficiency" [10] that 
has been developed with enthusiasm by the business world as a way for approaching simultaneously both environmental and economic sustainability.

Wyman [12] believes that companies that make sustainability a top priority, develop a solid base of knowledge, and put together the right strategic package will gain a huge lead on their competitors.

In Canada, long before "green solutions" become the fad, the North American railway industry was already implementing solutions that are environmentally smart and good business at the same time. Railways have for years been working towards: Cleaner air and lower emissions from diesel electric locomotives; Reduction of Greenhouse gasses; Reduction of runoff from open top cars; Movement of Invasive species; Noise \& Vibration pollution in urban areas; and Railway and rail yard site restoration. Maybe the public does not know, but railways have smaller $\mathrm{CO} 2$ footprint compared to road or air transportation. Rail transportation consumes less energy and the $\mathrm{CO} 2$ emissions are up to 10 times less [13].

The Low Carbon Rail Transport challenge of the Lima- Paris Action Agenda (LPAA)[14] will reduce GHG emissions through:

$>$ technical development and improved management leading to greater efficiency,

$>$ decarbonization of energy consumption

$>$ better use of existing rail assets (infrastructure

$>$ \& rolling stock),

$>$ investment to develop new rail networks

$>$ Benchmarking and reporting to drive improved performance $\&$ better inform transport policy.

A recent sustainability concepts Malaysia has is the implementation of Transit-Oriented Development (TOD). This is not just modernizing the public transport, or connecting communities to take advantage of quality public transportation, but also an encouragement for Malaysians to depend less on personal vehicles for mobility [15].

Kuala Lumpur is currently in the early stages of developing an integrated modern rail network compared to many other modern cities in the world, but adopting a sound TOD policy empowers people with the choice to walk, cycle or take public transportation.
This is an urban development response to growing traffic congestion and carbon emissions.

The MRT Sungai Buloh-Kajang (SBK) line is a good example to illustrate this point. Against the backdrop of criticism due to the size of the project and of the funds required for it, the MRT SBK line braved the storm and proved itself necessary for the country's growth.

Apart from providing better connectivity and accessibility, the project was also carefully planned to ensure TOD goals were achieved.

\section{Expected Results}

IoT is expected to see massive growth in the next ten to fifteen years, and most of that growth is expected to come from enterprise adoption, or what is now called IIoT, the industrial internet of things [16]. Advancements in IoT technology are changing the way people live, but behind the scenes, at manufacturing facilities around the world, IIoT is having an even greater impact. Coupled with making IIoT advancements sustainable, the future of railway industry seems bright.

Imagine a method of Intelligent transportation based on real-time traffic information and path optimization powered by IIOT. "Hi-Tech Rail (R) evolution" is a vision of an ecosystem where a train locomotive-a container - is embedded with hundreds of sensors that transmit data not only about the car itself, but also about its surroundings. It links the engine, the rail cars, the train yard, the tracks, and shipping ports efficiently, reliably, and safely in order to improve efficiency and eliminate waste [17].

The data captured along with advanced analytics is used to serve:

1. As a real time health monitor for the locomotive, providing real-time information about the locomotive's components, facilitating preventive and predictive maintenance and reducing downtime

2. To monitor the health of the entire rail ecosystem, including tracks and rails, further reducing both downtime and wait time.

3. To suggest routes and to complete course correction, relieving congestion in the rail ecosystem

4. To optimize the speed of the locomotive so as to attain fuel efficiency and fewer carbon emissions 
5. To devise smart yard solutions that provide "justin-time" loading and offloading operations

6. To better track of freight theft

7. To improve the audit process

8. To shed light on what needs to change or be made obsolete in the name of efficiency

This paper is an exploratory study preliminary for the implementation of a green sustainability strategic plan. The result of this study will be a comprehensive strategic plan for a greener and more sustainable railway industry for Malaysia. It will consider what the goals of the industry are, satisfy these goals through the implementation of IIoT, identify what strategies will be used, given the different applications needed by the industry from the IIoT technology, develop an action plan which will consider the resources that Malaysian transportation industry has.

\section{Conclusion}

Technology has been moving so fast that new ones are coming when the previous ones that arrived have not been fully understood yet. IIoT came so soon even when internet of things (IoT) has not been fully studied. In this case, these technologies' implication into green sustainability has not been considered that much yet. With the established advantage of IIoT into the railway transportation industry, it is but important to make sure that when implementing this technology green and sustainable development is a priority. Therefore, this study will develop a strategic plan making sure that IIoT implementation in the Malaysian Railway Transportation industry is green and sustainable.

\section{References}

1. G. Dickson, (n. d.) "Rail: the Backbone of Sustainable Transport", UNIFE European Rail Industry.

2. Railway Technology. (2017). Green Stations: Signalling the Future. [online] Available at: http://www.railway-technology.com/features/ feature106295/ [Accessed 20 Oct. 2017].

3. H. Briggs, Malaysia Stocktaking Report on Sustainable Transport and Climate Change Data, Policy, and Monitoring, November 2016, University of Kuala Lumpur - Malaysian Spanish Institute Leong Hau Kian, Focus Applied Technologies.

4. IoT Agenda. (2017). What is Industrial Internet of Things (IIoT)? - Definition from WhatIs.com. [online]

Available

at:

http://internetofthingsagenda.techtarget.com/defini tion/Industrial-Internet-of-Things-IIoT [Accessed 20 Oct. 2017].

5. P. Misal, (2017). IIoT and the Transformation of Railways. [online] Industrial IoT/Industrie 4.0 Viewpoints. Available at: https://industrialiot.com/2017/07/iiot-transformation-railways/ [Accessed 20 Oct. 2017].

6. M.B. Kulkarni, (2017). "IoT + IIoT + IIOT - Can be effective Sustainability lever for INDIA" [online] Available at: https://www.linkedin.com/pulse/iot-iiot- caneffective-sustainability-lever-india-kulkarni-m-b [Accessed 20 Oct. 2017].

7. S. Ashkin (2015), The Ashkin Group Sustainability Dashboard. [online] Clean Link. Available at: http://www.cleanlink.com/hs/article/TheDifference- Between-Green-And-Sustainability-13976 [Accessed 2 Oct. 2017].

8. YPEKA, 2012. Climate change. Ministry of Environment and climate change. Www.ypeka.gr

9. WCED (World Commission on Environmental and Development): Our Common Future. Oxford University Press, Oxford (1987)

10. Huesemann, M.H.: The failure of eco-efficiency to guarantee sustainability: future challenges for industrial ecology. Environ. Prog. 23, 264-270 (2004)

11. Wyman O. (2014) "From Green to Sustainable: Developing a Holistic Approach to Sustainable Business Growth." Marsh and McLennan Companies. Oliver Wyman's Sustainable Centre.

12. J. Bracken, "Railway Sustainability - A look for Greener Solutions - Canadian Heartland Training Railway", Canadian Heartland Training Railway, 2017. [Online]. Available: http://chtr.ca/railwayslook- greener-solutions/. [Accessed: 02- Nov2017].

13. Low Carbon Rail Transport Challenge UIC Initiative to Raise Energy Efficiency of Rail Sector", UNFCCC, 2017. [Online]. Available: http://newsroom.unfecc.int/lpaa/transport/lowcarbon- sustainable-rail-transport-challenge/. [Accessed: 01- Nov- 2017].

14. "Environmental sustainability in development Walking On The Edge | The Star Online", 
Thestar.com.my, 2017. [Online]. Available: https://www.thestar.com.my/opinion/columnists/w alking-on-the-edge/2017/09/29/environmentalsustainability- in-development-the-transportationindustry-may-be-one-of-the-nations-bi/. [Accessed: 05- Nov- 2017].

15. "3 Companies Leading with IIoT for Sustainable Production", The Steel Wire, 2017. [Online]. Available: http://globalblog.posco.com/3- companies-leading-iiot- sustainable-production/. [Accessed: 02- Nov- 2017].

16. P. Patra, "Hi-Tech Rail (R) evolution with Industrial Internet of Things (IIOT)", Capgemini.com, 2017. [Online]. Available: https://www.capgemini.com/2017/02/hi-tech-railrevolution-with-industrial-internet-of-thingsiiot/\#. [Accessed: 09- Nov- 2017]. 